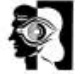

columns

\section{Evidence base and economic impact of community treatment orders}

The recent article by Owino (Psychiatric Bulletin, July 2007, 31, 241-243) highlights that community treatment orders are not greatly different from the current provisions of section 17 leave. I believe that the evidence base and economic impact of the new orders require further consideration.

A well-resourced, systematic and independent review of community treatment orders was conducted by Churchill (2007) This large review considered the findings of 72 studies conducted in 6 different countries over the last 30 years and concluded that there is very little evidence to suggest that they are associated with any positive outcomes. Furthermore, there is some evidence, and widespread agreement, that they cannot work as intended without adequate resources, and it is widely acknowledged that they will not work without the general support of mental healthcare providers.

The Cochrane review by Kisely et al (2005), which only includes two trials of community treatment orders, concludes that compulsory community treatment results in no significant difference in service use, social functioning or quality of life compared with standard care.

Regarding economic impact of the community treatment, the Kings Fund report by Lawton-Smith (2005) provides a detailed economic forecast. The report suggests that, over a period of 10-15 years, the number of people subjected to community treatment orders in England and Wales might rise to between 7800 and 13000 at any one time. The financial cost predictions in England and Wales will be $£ 3.4$ million in the first year, later increasing to $f 21.2$ million in 2014/15. This is to be considered against savings related to reduced use of hospital beds, of which it estimates saving $f 8.7$ million in the first year, increasing to $\mathrm{f} 47.7$ million in 2014/ 15 (Department of Health, 2006).

Given the lack of credible evidence to support community treatment orders and the indication by Owino that they are not greatly dissimilar to the current provisions of section 17 leave, it is difficult to understand why the government has pursued their implementation. Arguments that they have been more convinced by the political notion that the orders will help improve public safety must also be considered against the evidence that they may also lead to cost savings through closure of in-patient beds.

CHURCHILL, R. (2007) International Experiences of Using CommunityTreatment Orders. Institute of Psychiatry (http://www.iop.kcl.ac.uk/news/ downloads/Final2CTOReport8March07.pdf).
DEPARTMENT OF HEALTH (2006) Mental Health Bill 2006: Regulatory Impact Assessment. Department of Health.

KISELY, S. CAMPBELL, L. \& PRESTON, N. (2005)

Compulsory community and involuntary outpatient treatment for patients with severe mental disorders. Cochrane Database of Systematic Reviews, 3 , CD004408

LAWTON-SMITH, S. (2005) A Question of Numbers: The potential impact of community-based treatment orders in England and Wales. King's Fund.

Nuwan Galappathie Specialist Registrar in Forensic Psychiatry, Fromeside Clinic, Blackberry Hill, Bristol BS16 1ED, email: ngalappathie@doctors. org.uk

doi: 10.1192/pb.32.4.154

\section{'Forensic' - yet another form of stigma}

I read with interest the recent article by Turner \& Salter (Psychiatric Bulletin, January 2008, 32, 2-6) and O'Grady's commentary thereof (Psychiatric Bulletin, January 2008, 32, 6-7) on the borderline between forensic and general adult psychiatry, and I have to disagree with authors. I think it would be more healthy to concentrate on the actual patient rather than various artificial classifications that have been cooked up over the past years.

Prior to returning to forensic psychiatry I was mainly involved with the seriously mentally ill and their treatment. I have noticed that in fact the patients have changed very little, it is just the surroundings and legal paraphernalia, etc. that have. We still see people with severe psychosis who have not responded to treatment for a variety of reasons, some of them having personality disorder alongside psychotic illnesses and some with personality disorder per se. Our role as psychiatrists with such patients is key to achieving the maximum stabilisation to enable them to live as normal a life as possible within a setting that is suitable for them. I regard the rest of the paraphernalia and surrounding status as largely irrelevant, from a purely psychiatric point of view.

It would appear that there are many people who seek to interfere with the treatment and care of these patients, in particular members of the legal profession who have on occasion given me detailed instructions on what medical treatment to deliver to their client. Clearly they are no more qualified in that, than I am in giving them legal advice for my patients. It would seem that the cause of the increased number of 'forensic' patients is merely due to a breakdown in the quality of care given to these people in the community. I think the current political idea that one system fits all has been an abject failure, as indeed are all generalised solutions to the needs of individual patients. Obviously most people with severe mental illness will be able to live in some capacity in the community without any problems with violence or suicide, but there still remains a significant number who will never be able to do this, however much politicians seek to deny this. I have met many of such people and I can recognise their mental pain as they struggle to come to terms with a rigid system into which they will never fit.

In addition to these problems, of course, millions of pounds have been spent to enable us to reach this situation and it is frightening to think where this money might have been spent more usefully.

Mike Launer Medical Director and Consultant Psychiatrist, North West Services, Partnerships in Care, The Spinney, Everest Road, Atherton, Manchester M46 9NT, email: mlauner@ partnershipsincare.co.uk

doi: 10.1192/pb.32.4.154a

\section{Recruitment and retention of psychiatrists in low-income countries}

I have read the article Brown et al (Psychiatric Bulletin, November 2007, 31, 411-413) with great enthusiasm as its contents appear to be very relevant to low-income countries as well.

Recruitment into psychiatry seems to be a global issue. In addition to problems in recruitment, many psychiatrists and psychiatric trainees leave low-income countries in order to find more lucrative jobs in high-income countries. For instance, the Postgraduate Institute of Medicine, University of Colombo, Sri Lanka, has trained a reasonable number of psychiatrists over the past few decades. However, there are about 35 psychiatrists working in the country at present (about 2 psychiatrists per 1 million people). Obviously, this figure is grossly inadequate. Shortage of other professionals in the multidisciplinary team adds to the problem further. As a result of concentration of most of the psychiatrists in the cities, peripheries are poorly served.

In the Doctor of Medicine (MD; psychiatry) training programme in Sri Lanka there is a component of overseas training after completion of MD (Psychiatry) part 2 examinations. A survey among the trainees revealed that the majority preferred the UK centres for their overseas training and all indicated that they would like to return to Sri Lanka after their overseas training (details are available from the author upon request). However, it seems that once exposed to the overseas training and the Western 
lifestyle, many are reluctant to return. These issues were discussed at length at the recently held South Asian Federation of Psychiatric Association's Annual Academic Sessions in Kalutara, Sri Lanka.

We believe that there are a few options to reduce this crisis, for instance enhancing the recruitment of more doctors into psychiatry or improving the knowledge of psychiatry among primary care doctors. Already some medical schools in Sri Lanka (e.g. University of Kelaniya and University of Colombo) have addressed this issue and increased the psychiatry training component in their undergraduate curricula. One of them is Colombo Medical School where psychiatry is assessed as a separate subject in the final Bachelor of Medicine and Bachelor of Surgery (MBBS) examination. Soon psychiatry will be incorporated as a separate subject at the final year assessment at the Faculty of Medicine, University of Kelaniya.

The importance of improving the quality of undergraduate teaching in order to enhance the recruitment of medical graduates to the field of psychiatry has been emphasised (Sierles et al, 2003). When medical students are more knowledgeable, fear and stigma associated with psychiatry, which seems to be more prevalent in low-income countries such as Sri Lanka, become less prominent.

A recent survey carried out among undergraduates in medical schools in the Western Province of Sri Lanka demonstrated that the career choice in psychiatry is about $2 \%$, which is less than in the Western world (details are available from the author). A study in Spain has shown that the career choice for psychiatry was $6 \%$, compared with $4.5 \%$ in the USA (Pailhez et al, 2005).

Psychiatry seems to be a less attractive medical field globally. Overworked psychiatrists with minimum rewards for their work tend to lose their interest in the profession, which can adversely influence the quality of care and teaching. Psychiatrists should be aware of factors that will help them prevent that.

As medical teachers and practising psychiatrists we should also be aware of the problems encountered in psychiatry to enhance the recruitment and retention of psychiatrists.

SIERLES, F. S., YAGER, J. \& WEISSMAN, S. H. (2003) Recruitment of US medical graduates into psychiatry: reasons for optimism, sources of concern. Academic Psychiatry, 27, 252-259.

PAlLHEZ, G, BULBENA, A. \& BALON, R. (2005) Attitudes to psychiatry: a comparison of Spanish and US medical students. International Psychiatry, 10 $6-8$

K. A. L. A. Kuruppuarachchi Professor of Psychiatry, Faculty of Medicine, University of Kelaniya, PO Box 6, Thalagolla Road, Ragama, Sri Lanka, email: alithkuruppu@|ycos.com

doi: 10.1192/pb.32.4.154b

\section{New Ways of Working: implications for patients in adult psychiatry}

We read with interest the article by Mehta et al (Psychiatric Bulletin, December 2007, 31, 381-384). Community mental health teams' case-loads comprise a variety of service users such as stable patients requiring 'routine followups', long-term patients caught in the system, 'revolving door' patients (who tend to slip through the net), patients requiring social care and newly referred individuals. There is a tendency for the 'status quo' service users on standard Care Programme Approach to remain in the mental health system for routine outpatients.

It is difficult to define a 'complex patient' as their and the carer's opinions may differ from the objective. However, we think the authors' parameter of defining a 'complex patient' based on time elapsed since the last appointment, level of Care Programme Approach and lack of objective clinical activity are a good measure of complexity.

The New Ways of Working emphasises the role of a consultant psychiatrist in complex cases. However, after more than 2 years from its introduction the actual initiative is still patchily distributed within organisations and all its main principles are not fully accepted. We agree with the authors that once the New Ways of Working is implemented, routine followups would be expected to be eliminated from consultant's care.

The consultants and the multidisciplinary teams should change the current practice, laying more emphasis on the brief short-term interventions, promoting recovery, self-dependence and timely discharge to primary care. Stable patients can be effectively managed in primary care and an initiative to improve liaison with general practitioners can facilitate such people to be followed-up.

However, it would be interesting to see how the new breed of consultants who start their career under New Ways of Working would function in the long-term. In trying to use the skills of a consultant psychiatrist more effectively to deliver their expertise more 'timely' than 'routinely', there is a danger that they may end up in dealing with 'complex patients' only. Consultants may also lose the skills to manage 'routine patients', who are far more common than 'complex patients' in a psychiatric practice.

*Arvind Sharma Consultant Psychiatrists and Medical Lead, Holly Lodge Community Mental Health Team, 45 Church Lane, Cheshunt, Hertfordshire EN8 ODR,email: arvind.sharma@hertspartsft. nhs.uk, Venkat Raj Goud Kondan Locum Consultant, Community Mental HealthTeam Ware, Hertfordshire Partnership Foundation Trust,
Hertfordshire, Ayesha Naveed Specialty Registrar Year 2, Community Mental HealthTeam Cheshunt, Hertfordshire Partnership Foundation Trust, Hertfordshire

\section{Child and adolescent in-patient units - room for expansion}

We read with interest the concerns expressed in a recent article by Cotgrove et al (Psychiatric Bulletin, December 2007, 31, 457-459). The Ashfield Unit is an adolescent unit able to accept emergency admissions that opened in 2003 in recognition of a lack of emergency provision leading to delayed admissions and inappropriate use of paediatric or adult psychiatric wards. Our experience since opening has been in contrast to the concerns expressed by Cotgrove et al. We have not had inappropriate admissions and there have been no difficulties with recruitment and retention of staff.

What has been unexpected is the high level of violence, aggression and risk to others in some young people. This may be similar to the experience in adult psychiatry in recent years, with only the most disturbed patients being referred for admission into in-patient psychiatric units. There has been a higher than expected need for intensive nursing care in a lowstimulus environment - a third of our young people presenting with psychosis required the use of the intensive nursing area at some point in their admission (Cullen et al, 2006).

Although O'Herlihy et al in their paper (2007) demonstrate a dramatic increase in forensic provision, we would recommend an increase in provision of a spectrum of psychiatric intensive care units for adolescents alongside general and acute adolescent in-patient units, which could be used flexibly to allow the young person to be rehabilitated back onto an open ward as soon as possible.

CULLEN, L.,THOMAS, B. \& SMITH, P. (2006) A novel acute admission and assessment service for teenagers with first episode psychosis. Schizophrenia Research, 86 (supp 1), $\mathbf{5 1 6 8 .}$

O' HERLIHY, A., LELLIOTT, P, BANNISTER, D., et al (2007) Provision of child and adolescent mental health in-patient services in England between 1999 and 2006. Psychiatric Bulletin, 31, 454-456.

*Nicole Karen Fung Specialist Registrar in Child and Adolescent Psychiatry, Ashfield Unit, Parkview Clinic, 60 Queensbridge Road, Moseley, Birmingham B138QE, email:nkf@doctors.org.uk, Linda Cullen Consultant Child and Adolescent Psychiatrist, Ashfield Unit

doi: $10.1192 / p b .32 .4 .155 a$ 